\title{
Adverse Events of Monoclonal Antibodies Used for Cancer Therapy
}

\author{
Mei Guan, ${ }^{1}$ Yan-Ping Zhou, ${ }^{1}$ Jin-Lu Sun, ${ }^{2}$ and Shu-Chang Chen ${ }^{1}$ \\ ${ }^{1}$ Department of Oncology, Peking Union Medical College Hospital, Peking Union Medical College and \\ Chinese Academy of Medical Sciences, Beijing 100730, China \\ ${ }^{2}$ Department of Allergy, Peking Union Medical College Hospital, Peking Union Medical College and \\ Chinese Academy of Medical Sciences, Beijing 100730, China
}

Correspondence should be addressed to Jin-Lu Sun; sunj15@yahoo.com

Received 6 August 2014; Accepted 24 August 2014

Academic Editor: Ji-Fu Wei

Copyright (C) 2015 Mei Guan et al. This is an open access article distributed under the Creative Commons Attribution License, which permits unrestricted use, distribution, and reproduction in any medium, provided the original work is properly cited.

In 1997, the first monoclonal antibody (MoAb), the chimeric anti-CD20 molecule rituximab, was approved by the US Food and Drug administration for use in cancer patients. Since then, the panel of MoAbs that are approved by international regulatory agencies for the treatment of hematopoietic and solid malignancies has continued to expand, currently encompassing a stunning amount of 20 distinct molecules for 11 targets. We provide a brief scientific background on the use of MoAbs in cancer therapy, review all types of monoclonal antibodies-related adverse events (e.g., allergy, immune-related adverse events, cardiovascular adverse events, and pulmonary adverse events), and discuss the mechanism and treatment of adverse events.

\section{Introduction}

Engineered monoclonal antibodies (MoAbs) represent a significant addition to the therapeutic armamentarium for a variety of malignancies. Adverse events (AEs) of these new regimens are described to be mild compared with those of classical chemotherapy. Twenty MoAbs are currently registered and approved for the treatment of a range of different cancers. These MoAbs are specific for 11 targets. Five of these molecules are directed against the B-lymphocyte antigen CD20, 3 against human epidermal growth factor receptor 2 (HER2 or ErbB2), 3 against the epidermal growth factor receptor (EGFR), 2 against vascular endothelial growth factor (VEGF), and 1 each against epithelial cell adhesion molecule (EpCAM), CD30, CD52, tumor necrosis factor (ligand) superfamily member 11 (TNFSF11, also known as RANKL), cytotoxic T lymphocyte-associated protein 4 (CTLA-4), programmed death 1 protein (PD-1) and interleukin-6 (IL-6) are summarized in Table 1. Common adverse events (AEs) include allergy (rash, infusion reactions), diarrhea, hypertension, proteinuria, hypothyroidism, and hepatotoxicity. Certain toxicities are caused by on-target, mechanism-associated effects, which can be stratified by whether or not the targets are relevant to response. Other toxicities are off-target and may be caused by immune reactions or toxic metabolites. Here, we review monoclonal antibodies-related AEs and management of patients displaying these reactions.

\section{Drug Allergy}

Historically, immunologic reactions have been divided into four categories (I to IV) according to the Gell and Coombs system. Drugs are most commonly implicated in type I reactions. These reactions, mediated by IgE antibodies are also known as anaphylactic hypersensitivities and are relatively uncommon after administration of MoAbs. Immediate hypersensitivity may affect a single organ such as the nasopharynx (allergic rhinitis), eyes (conjunctivitis), mucosa of mouth/throat/tongue (angioedema), bronchopulmonary tissue (asthma), gastrointestinal tract (gastroenteritis), and skin (urticaria, eczema) or multiple organs (anaphylaxis). They cause symptoms that range from minor itching and inflammation to death. Symptoms associated with anaphylaxis are shown in Figure 1 [1]. Anaphylaxis has been reported for cetuximab, rituximab, trastuzumab, pertuzumab, obinutuzumab, ofatumumab, tositumomab, and 
TABLE 1: Monoclonal antibodies (MoAbs) approved for cancer therapy.

\begin{tabular}{|c|c|c|c|c|}
\hline $\mathrm{MoAb}$ & Trade name & Target & Type & Indication(s) \\
\hline Cetuximab & Erbitux & EGFR & Chimeric IgG1 $\kappa$ & HNC and colorectal cancer \\
\hline Panitumomab & Vectibix & EGFR & Human IgG2א & Colorectal carcinoma \\
\hline Nimotuzumab & Nimotuzumab & EGFR & Human IgGh-R3 & HNC \\
\hline Bevacizumab & Avastin & VEGFR & Humanized IgGl $\kappa$ & Colorectal, renal, lung, and brain cancer \\
\hline Ramucirumab & Cyramza & VEGFR & Humanized IgGl $\kappa$ & Gastric or gastresophageal junction cancer \\
\hline Trastuzumab & Herceptin & HER2 & Humanized IgG1 $\kappa$ & $\begin{array}{c}\text { Breast cancer, } \\
\text { gastric or gastroesophageal junction cancer }\end{array}$ \\
\hline Trastuzumabemtansine & Kadcyla & HER2 & Humanized IgGl $\kappa$ & Breast cancer \\
\hline Pertuzumab & Perjeta & HER2 & Humanized IgG1 $\kappa$ & Breast cancer \\
\hline Alemtuzumab & Campath & CD52 & Humanized IgG1 $\kappa$ & Chronic lymphocytic leukemia \\
\hline Rituximab & $\begin{array}{l}\text { Rituxan } \\
\text { MabThera }\end{array}$ & $\mathrm{CD} 20$ & Chimeric IgG1 $\kappa$ & $\begin{array}{c}\text { Chronic lymphocytic leukemia and non-Hodgkin } \\
\text { lymphoma }\end{array}$ \\
\hline Ofatumumab & Arzerra & $\mathrm{CD} 20$ & Human IgGl $\kappa$ & Chronic lymphocytic leukemia \\
\hline Obinutuzumab & Gazyva & CD20 & Human IgG1 & CLL \\
\hline Ibritumomab & Zevalin & $\mathrm{CD} 20$ & Murine IgG1 $\kappa$ & Non-Hodgkin lymphoma \\
\hline Tositumomab & Bexxar & $\mathrm{CD} 20$ & Murine $\operatorname{IgG} 2 \mathrm{a} \lambda$ & Non-Hodgkin lymphoma \\
\hline Brentuximab Vedotin & Adcetris & CD30 & Chimeric IgGl $\kappa$ & Hodgkin's and anaplastic large cell lymphoma \\
\hline Ipilimumab & Yervoy & CTLA-4 & Human IgG1 $\kappa$ & Melanoma \\
\hline Catumaxomab & Removab & EpCAM & $\begin{array}{l}\text { Rat IgG2b/mouse } \\
\text { IgG2a bispecific }\end{array}$ & Malignant ascites in patients with ePCaM + cancer \\
\hline Denosumab & $\begin{array}{l}\text { Prolia } \\
\text { Xgeva }\end{array}$ & RANKL & Human IgG2א & $\begin{array}{l}\text { Breast cancer, prostate cancer, and giant cell tumors of } \\
\text { the bone }\end{array}$ \\
\hline Nivolumab & Opdivo & PD-1 & Human IgG4 & Melanoma \\
\hline Siltuximab & Sylvant & IL-6 & Chimeric IgG1 $\kappa$ & $\begin{array}{l}\text { Castleman disease, multicentric (in patients who are } \\
\text { HIV negative and HHV-8 negative) }\end{array}$ \\
\hline
\end{tabular}

ibritumomab, and these last two MoAbs have also been reported to cause bronchospasm and angioedema [2-6].

A high prevalence of hypersensitivity reactions to cetuximab have been reported in some areas of the United States. In most subjects who had a hypersensitivity reaction to cetuximab, IgE antibodies against cetuximab were present in serum before therapy [7-10]. The antibodies are specific for an oligosaccharide, galactose- $\alpha$-1,3-galactose, which is present on the Fab portion of the cetuximab heavy chain. The presence of such antibodies is predictive of anaphylaxis, and pretreatment testing would help in minimizing the risk of anaphylaxis associated with cetuximab [11].

2.1. Standard Infusion Reactions (SIR). Nearly all MoAbs share a risk for standard infusion reactions (SIR), but certain drugs (e.g., rituximab, cetuximab, alemtuzumab, ramucirumab, obinutuzumab, and ofatumumab) are associated with a high enough risk to warrant special precautions. The most common symptoms and signs are dyspnea, nausea, headache, and abdominal pain. Most reactions are mild; only approximately $0.3 \%$ of patients have serious infusion reactions with features of anaphylaxis (bronchospasm, hypotension, and angioedema). Standard infusion reactions typically develop within 30 minutes to two hours after the initiation of drug infusion, although symptoms may be delayed for up to 24 hours. The majority of reactions occur after the first or second exposure to the agent, but between 10 and 30\% occur during subsequent treatments. Rituximab, obinutuzumab, and trastuzumab induce the highest incidence of SIR. In general, the incidence of MoAb induced IR varies from 15$20 \%$ for cetuximab (3\% grade $3 / 4$ ) and $40 \%$ for trastuzumab first infusion $(<1 \%$ grade $3 / 4)$ to $77 \%$ for rituximab first infusion (10\% grade $3 / 4)$. Infusion reactions are markedly less common after the initial infusion [12]. The manufacturer reports a frequency of 77,30 , and $14 \%$ during the first, fourth, and eighth infusions of rituximab, respectively. The incidence of IR to the humanized MoAbs bevacizumab, panitumumab and nimotuzumabis is significantly lower at $<3 \%$ $(0.2 \%$ grade $3 / 4)$. The mechanism underlying MoAb-related infusion reactions remain unclear, but most are thought to be related to antigen-antibody interactions precipitating cytokine release $[5,6]$. It is the most predictable reaction that occurs with rituximab, and is thought to be caused by the interaction of the drug with the target antigen (CD20) on circulating cells, followed by cytokine release from lymphocytes. Evidence for this mechanism includes the observation that severe and fatal reactions have typically occurred in patients with high numbers of circulating lymphocytes bearing the target antigen [5]. 

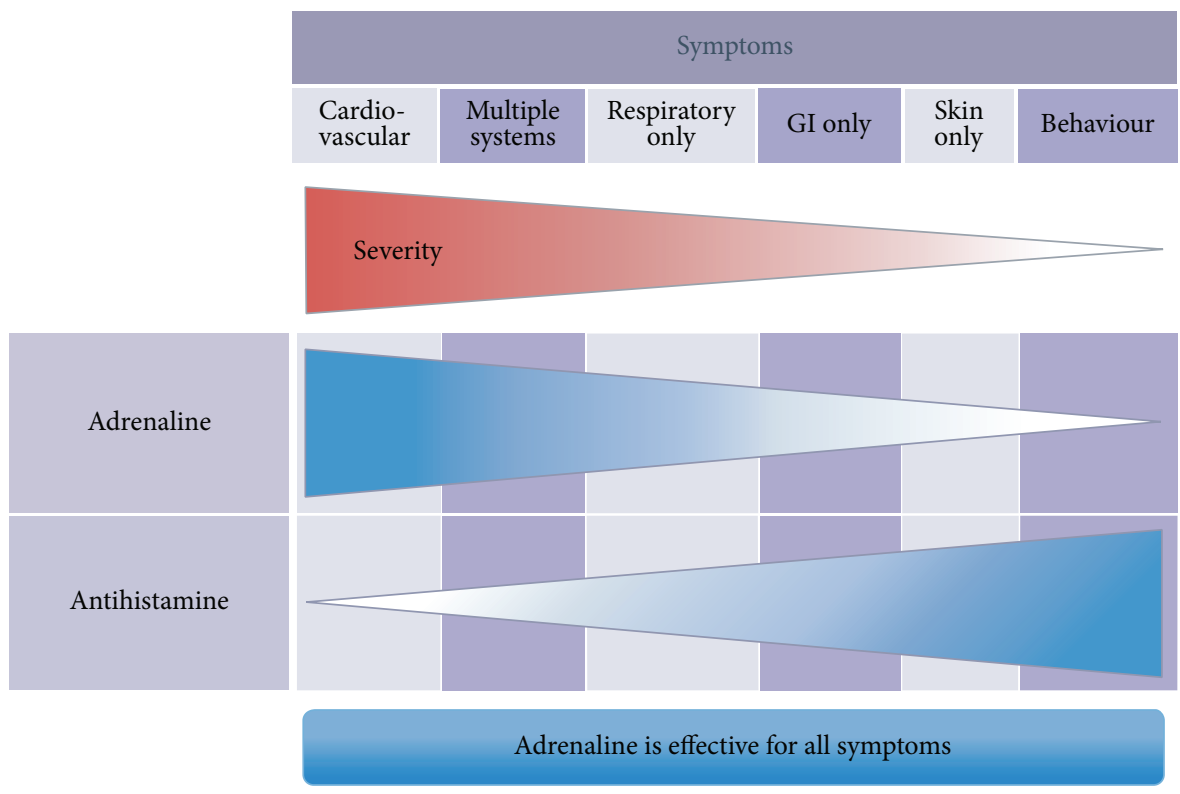

GI, gastrointestinal.

FIGURE 1: Symptoms associated with anaphylaxis.

2.2. Serum Sickness (A Delayed Type III Allergic Reaction). Serum sickness has been reported with rituximab. Symptoms include fever and arthralgia with a morbilliform skin eruption that often has acral accentuation. The reaction typically develops one to two weeks after treatment and is accompanied by laboratory evidence of complement activation (depressed C3 and C4 levels) and tissue inflammation (elevated erythrocyte sedimentation rate and C-reactive protein) [13]. Chimeric MoAbs have the potential to induce serum sickness. Recently, it has been reported that rituximabinduced serum sickness-like reactions occur in $1-20 \%$ of patients [14].

\subsection{Treatment}

2.3.1. Prevention. Pharmacologic prophylaxis with a histamine $\mathrm{H} 1$ receptor antagonist is recommended prior to each infusion of ramucirumab. Pharmacologic prophylaxis with antihistamines and acetaminophen with or without a glucocorticoid is suggested for high-risk agents (i.e., rituximab, first infusion of cetuximab in a patient who resides in a high-risk area and intravenous alemtuzumab). Despite premedication, clinicians must be prepared for an infusion reaction to occur during each drug administration $[6,15]$.

2.3.2. Mild to Moderate SIR. If the reaction is limited to mild or moderate symptoms of SIR (grades 1 or 2), without features suggestive of anaphylaxis, drug infusion should be temporarily stopped and assessment of airway, breathing, circulation, and mentation should rapidly occur. IV administration of $50 \mathrm{mg}$ of diphenhydramine and $650 \mathrm{mg}$ of acetaminophen may provide symptomatic relief. Once symptoms have resolved, resumption of the drug infusion at a slower rate may permit treatment continuation with close monitoring [6].

2.3.3. Severe SIR or Anaphylaxis. Severe SIR (grades 3/4) or reactions of any severity with any features of anaphylaxis (e.g., generalized urticaria, wheezing, hypotension, and angioedema) require prompt recognition and treatment. Clinical criteria for diagnosing anaphylaxis can be seen in Table 2. Recommendations for emergency management are shown in Table 3 [1]. The first line drug treatment is adrenaline.

2.3.4. Rechallenge. Once the acute event has subsided, the issue of rechallenge must be addressed. Patients with severe infusion reaction or anaphylaxis to cetuximab can be safely switched to pannitumumab. The decision to attempt retreatment depends upon the drug, the severity of the reaction, the cancer being treated, and whether there are reasonable treatment alternatives $[5,6]$.

2.3.5. Desensitization. Experience with desensitization to MoAbs is relatively limited. At some institutions, these are only performed by allergy specialists [63].

\section{Immune-Related Adverse Events (irAEs)}

Ipilimumab is a monoclonal antibody that targets CTLA4 , thus unleashing an immune reaction against the tumor. CTLA-4 is a surface protein expressed on activated and 
TABLE 2: Clinical criteria for diagnosing anaphylaxis.

Anaphylaxis is highly likely when anyone of the following three criteria is fulfilled:

(1) acute onset of an illness (minutes to several hours) with involvement of the skin, mucosal tissue, or both (e.g., generalized hives, pruritus or flushing, swollen lips, tongue, and uvula and at least one of the following:

(a) respiratory compromise (e.g., dyspnea, wheeze-bronchospasm, stridor, reduced PEF, and hypoxemia),

(b) reduced BP or associated symptoms of end-organ dysfunction (e.g., hypotonia [collapse], syncope, and incontinence);

(2) two or more of the following that occur rapidly after exposure to a likely allergen for that patient (minutes to several hours):

(a) involvement of the skin-mucosal tissue (e.g., generalized hives, itch-flush, and swollen lips, tongue, and uvula),

(b) respiratory compromise (e.g., dyspnea, wheeze-bronchospasm, stridor, reduced PEF, and hypoxemia),

(c) reduced BP or associated symptoms (e.g., hypotonia [collapse], syncope, and incontinence),

(d) persistent gastrointestinal symptoms (e.g., crampy abdominal pain, vomiting);

(3) reduced BP after exposure to known allergen for that patient (minutes to several hours):

(a) infants and children: low systolic BP (age specific) or $>30 \%$ decrease in systolic BP*

(b) adults: systolic BP of $<90 \mathrm{mmHg}$ or $>30 \%$ decrease from that person's baseline

Notes

PEF, peak expiratory flow; BP, blood pressure.

* Low systolic blood pressure for children is defined as $<70 \mathrm{mmHg}$ from 1 month to 1 year, less than $(70 \mathrm{mmHg}+[2 \times$ age $])$ from 1 to 10 years and $<90 \mathrm{mmHg}$ from 11 to 17 years.

TABLE 3: Emergency management: recommendations.

Recommendation

Evidence Level

Grade

First-line intervention: adrenaline

Adrenaline is potentially lifesaving and must therefore promptly be administered as the first-line treatment for the emergency management of anaphylaxis.

Earlier administration of adrenaline should be considered on an individual basis when an allergic reaction is likely to develop into anaphylaxis.

Adrenaline should be administered by intramuscular injection into the midouter thigh.

In patients requiring repeat doses of adrenaline, these should be administered at least 5 min apart.

With inadequate response to two or more doses of intramuscular adrenaline, adrenaline may be

administered as an infusion by appropriately experienced intensive care, emergency department, and critical care physicians, with appropriate cardiac monitoring.

\section{Second-line interventions}

Trigger of the anaphylaxis episode should be removed.

Help should be called promptly and simultaneously with patient's assessment.

Patients experiencing anaphylaxis should be positioned supine with elevated lower extremities if they have circulatory instability, sitting up if they have respiratory distress, and in recovery position if unconscious.

High-flow oxygen should be administered by face mask to all patients with anaphylaxis.

Intravenous fluids (crystalloids) should be administered (boluses of $20 \mathrm{~mL} / \mathrm{kg}$ ) in patients experiencing cardiovascular instability.

Inhaled short-acting beta-2 agonists should additionally be given to relieve symptoms of bronchoconstriction.

\section{Third-line interventions}

Oral H1- (and H2-) antihistamines may relieve cutaneous symptoms of anaphylaxis.

V D

I B

V

$\mathrm{D}$

IV

$\mathrm{D}$

Systemic glucocorticosteroids may be used as they may reduce the risk of late-phase respiratory symptoms. High-dose nebulized glucocorticoids may be beneficial for upper airway obstruction.

\section{Monitoring and discharge}

Patients who presented with respiratory compromise should be closely monitored for at least $6-8 \mathrm{~h}$, and patients who presented with circulatory instability require close monitoring for $12-24 \mathrm{~h}$.

Before discharge, the risk of future reactions should be assessed and an adrenaline autoinjector should be prescribed to those at risk of recurrence.

Patients should be provided with a discharge advice sheet, including allergen avoidance measures (where possible) and instructions for the use of the adrenaline autoinjector.

Specialist and food allergy specialist dietitian (in food anaphylaxis) followup should be organized. Contact information for patient support groups should also be provided.

$\mathrm{D}$

西
$\mathrm{V}$

$\mathrm{V}$

V

V

V

V

D

D

D

D

D

$\begin{array}{ll}\mathrm{I} & \mathrm{B} \\ \mathrm{V} & \mathrm{D}\end{array}$

D

B

D

V D

V D

V D

V D 
regulatory $\mathrm{T}$ cells and is upregulated in malignancy [56]. Immune-related adverse events (irAEs) can occur at any point during treatment with ipilimumab, but often first present around the third or fourth dose. The incidence of hypophysitis due to ipilimumab has been reported to range from 0 to $17 \%$ in clinical trials, though the mechanism of pituitary injury remains unknown. Other immune-related adverse events include hepatotoxicity, or failure of the thyroid gland (autoimmune thyroiditis), the adrenal gland, and gonadal axis, and enterocolitis, which can be serious or lifethreatening (any grade $30 \%-35 \%$, grade $3-5$ diarrhea $5 \%-$ $8 \%$ ) [57]. It remains unclear whether the effects result from $\mathrm{T}$ cells specifically acting against antigens shared by tumor and normal cells or from the concomitant activation of multiple $\mathrm{T}$ cell populations with separate antihost and antitumor activity $[64,65]$. Current recommendations include baseline TSH and free T4 and monitoring every 3 weeks during ipilimumab treatment and every 2-3 months following completion. For patients with severe or life-threatening grade $3 / 4$ AEs, treatment with ipilimumab should be permanently discontinued and high doses of corticosteroids (prednisone 1 to $2 \mathrm{mg} / \mathrm{kg} /$ day or equivalent) are indicated [56].

Radioimmunotherapy (RIT) refers to the use of monoclonal antibodies that are linked to radioisotopes (e.g., yttrium-90). Two drugs have been approved by the United States FDA to be used in treatment of relapsed or refractory CD20 positive, low-grade, follicular, or transformed non-Hodgkin's lymphoma (NHL). Ibritumomabtiuxetan (Zevalin) is a murine anti-CD20 monoclonal antibody conjugated to yttrium-90 [2]. Tositumomab (Bexxar) is a murine anti-CD20 monoclonal antibody conjugated with radioactive iodine-131 [3]. RIT may also lead to hypothyroidism; patients should receive thyroid-blocking medications beginning at least 24 hours prior to tositumomab and continued for 2 weeks after the therapeutic dose. Nivolumab is a humanized monoclonal antibody that targets the PD-1 protein. Immune-related adverse events are the most common side effects, and the skin and gastrointestinal tract are the most often affected organ systems and less frequently hepatic, endocrine, and neurologic events occur $[66,67]$.

\section{Cardiovascular AEs}

Cardiac adverse events have occurred with specific MoAbs, including bevacizumab, trastuzumab, trastuzumabemtansine, pertuzumab, ofatumumab, and rituximab $[5,22,38,45$, $68,69]$.

4.1. Hypertension. VEGF plays a key role in the maintenance of vascular homeostasis via mediation of the production of the vasodilator nitric oxide and decrease of vascular resistance through the generation of new blood vessels $[68,70-$ 72]. The overall incidence of bevacizumab-induced hypertension is approximately 12 to $34 \%$, with severe hypertension in 5 to $18 \%$. Hypertension has been proposed to be a clinical biomarker of antitumor activity [73]. The incidence rate of hypertension for ramucirumab was lower than bevacizumab (all grades: 6\%; grades 3/4: 8\%) [74].

4.2. Arterial and Venous Thromboembolism. An increased risk for arterial thromboembolic events (ATEs) has been linked to the use of bevacizumab and ramucirumab [23, $24,28,75]$. The overall incidence of bevacizumab-induced thromboembolism is $\leq 21 \%$ (grades $3 / 4: 15 \%$ ) and consists of venous thromboembolism (all-grade: $8 \%$; grades $3 / 4: 5 \%$ to $7 \%$ ) and arterial thrombosis (all-grade: $6 \%$; grades $3 / 4: 3 \%$ ). In a pooled analysis of 1,745 patients, of whom 963 were treated with bevacizumab ( $24 \%$ breast cancer), the incidence of thromboembolic events was $4 \%$ in patients treated with bevacizumab plus chemotherapy, and $2 \%$ in those treated with chemotherapy alone [75]. Ramucirumab-induced arterial thrombosis (including myocardial infarction, cardiac arrest, cerebrovascular accident, and cerebral ischemia) was seen in $2 \%$ patients [28].

4.3. Congestive Heart Failure (CHF). A meta-analysis of five randomized trials involving a total of 3,784 metastatic breast cancer patients analyzed the incidence of congestive heart failure (CHF) when using chemotherapy with or without bevacizumab. The incidence of high-grade CHF was $1.6 \%$ in patients treated with bevacizumab and $0.4 \%$ in patients who did not receive this drug [24]. In NSABP B31, asymptomatic decrease in LVEF occurred in $14 \%$ of patients, requiring discontinuation of trastuzumab [22]. Endomyocardial biopsy was performed in a limited number of patients exposed to trastuzumab and demonstrated no significant abnormalities [31]. The incidence of severe CHF in the trastuzumab adjuvant studies is in the range of $1 \%$ to $4 \%$. In the Herceptin Adjuvant trial (HERA), with 3.6 years of median followup, all cases of severe CHF occurred during trastuzumab treatment; however, the cardiac performance of the majority of affected patients improved when trastuzumab was withdrawn [32]. The incidence of CHF in older patients treated with trastuzumab is expected to be higher than in the overall population evaluated in large clinical trials [33]. Combining anti-HER2 and anti-VEGF drugs has consequently emerged as an important strategy to optimize the targeted treatment of breast cancer. The bevacizumab plus trastuzumab combination was evaluated in 50 heavily pretreated metastatic breast cancer patients [76]. This combination was associated with a $30 \%$ incidence of asymptomatic LVEF decrease, $2 \%$ grade 4 LVEF decrease, and 36\% incidence of hypertension. In phases I-III of trials of pertuzumab, cardiac dysfunction was seen in $4.5-14.5 \%$ of patients with pertuzumab treatment and cardiac dysfunction was usually grade 1/2 [39]. Cardiotoxicity of pertuzumab was usually reported in combination with trastuzumab and no additive cardiotoxicity was reported with addition of pertuzumab to trastuzumab [38]. A phase II study evaluated trastuzumab-DM1 in 107 patients pretreated with anthracyclines, trastuzumab, taxanes, capecitabine, and lapatinib. Reduction in LVEF was observed in two patients [69]. 
4.4. Hemorrhage. All VEGF-targeted agents have been associated with an increased risk of hemorrhage. This is most commonly grade 1 epistaxis, though more serious, and in some cases, fatal hemorrhagic events have occurred, including hemoptysis (particularly in patients with squamous cell lung cancer), gastrointestinal bleeding, hematemesis, intracerebral hemorrhage, epistaxis, and vaginal bleeding. The overall risk of major bleeding is approximately 2 to $3 \%$. A total of 12,917 patients from 17 RCTs treated with bevacizumab had a significantly increased risk of cerebrovascular events compared with patients treated with control medication, with a relative risk of 3.28 (95\% CI, 1.97-5.48). The risks of CNS ischemic events and CNS hemorrhage were increased compared with control, with relative risk (RRs) of 3.22 (95\% CI, 1.71-6.07) and 3.09 (95\% CI, 1.36-6.99), respectively. Risk varied with the bevacizumab dose, with RRs of 3.97 (95\% CI, 2.15-7.36) and 1.96 (95\% CI, 0.76-5.06) at 5 and $2.5 \mathrm{mg} / \mathrm{kg} /$ week, respectively [25].

4.5. Treatment. To prevent cardiovascular adverse events, the physician should perform a pretreatment evaluation and screening, including formal risk assessment for potential cardiovascular complications. Preexisting hypertension should be identified and treated before using these agents. Caution and close serial monitoring of LVEF are warranted during therapy with bevacizumab in older adults and those with a history of hypertension, heart disease or anthracycline exposure. Cardiac troponin and amino-terminal fragment Btype natriuretic peptide (NT proBNP) have been the most frequently assessed biomarkers for cardiac injury and will be briefly described. Cardiac troponin is a medium-sized protein that regulates the cardiac contractile elements actin and myosin. The NT proBNP is useful for diagnosing cardiac failure in breathless patients but its utility for identifying subclinical cardiac pathology is unclear [77]. MoAbs should be discontinued for any severe ATE/VTE. Antiangiogenic therapy is associated with impairment of wound healing. It is recommended to withhold ramucirumab treatment prior to surgery. After surgery, clinical judgment dictates when to resume based on adequate wound healing. It is recommended that bevacizumab should be discontinued at least 28 days prior to surgery and should not be reinitiated for at least 28 days after surgery and until wound is fully healed [26, 28].

\section{Pulmonary AEs}

There are several complications that affect the lungs associated with the use of MoAbs, including interstitial lung disease (ILD), hemorrhage, trachea-esophageal fistula, and thromboembolic disease. Since the mechanisms underlying such lung injuries have generally not been uncovered, any classification on the basis of pathogenesis is difficult. Adverse events can be grouped into 4 main categories: interstitial pneumonitis and fibrosis, acute respiratory distress syndrome (ARDS), bronchiolitis obliterans organizing pneumonia (BOOP), and hypersensitivity reactions. Signs, symptoms, and clinical findings include dyspnea, cough, fatigue, and pulmonary opacities. Because signs and symptoms are generally nonspecific, the diagnosis usually remains one of exclusion $[16,34,35,43,78,79]$.

Once again, rituximab is the most implicated MoAb, inducing a heterogeneous spectrum of lung disorders. In 2003 , the reported rate of possible drug-induced lung injury was $<0.03 \%$ from $>540,000$ exposed patients. BOOP is the most common clinical diagnosis of rituximab-induced lung disease, followed by interstitial pneumonitis, ARDS, and hypersensitivity pneumonitis. Acute or subacute rituximabinduced lung disease, most notably organizing pneumonia, most likely reflects a hypersensitivity reaction to the potentially immunogenic chimeric anti-CD20 antibody. Arguments that support a hypersensitivity reaction include the recurrence and increasing severity of the symptoms from one infusion to the next, occurrence during the third month on average, responsiveness to steroid therapy (delayed onset 15 days after methylprednisolone infusion and favorable outcome with steroid therapy), rash and eosinophilia, BALF lymphocytosis, and histological pattern of organizing pneumonia in many patients [43]. Interstitial lung disease (ILD) has been reported in treatment with cetuximab and transtuzumab [16, 34].

Discontinuation of MoAb is advised in any patient who develops ILD or acute respiratory distress syndrome (ARDS) during treatment. Improvement following treatment with glucocorticoids has been reported; however, the role of glucocorticoid therapy in MoAb-induced pulmonary AEs has not been formally studied $[35,78,79]$.

\section{Proteinuria/Nephrotic Syndrome}

Bevacizumab is associated with proteinuria, though rarely in the nephrotic range $(>3.5 \mathrm{~g} / 24$ hours) and even more rarely associated with the nephritic syndrome [27, 80, 81]. Hypertension frequently accompanies proteinuria. Proteinuria is usually an asymptomatic event detected only through laboratory analysis. Reports of renal biopsies among patients with proteinuria receiving VEGF-targeted agents are sparse; when reported, the most common causative agent was bevacizumab. Histologic findings include thrombotic microangiography, collapsing glomerulopathy, and isolated reports of cryoglobulinemic and immune complex glomerulonephritis. The overall incidence of mild proteinuria in patients treated with bevacizumab ranges from 21 to up to $63 \%$, but grade 3 or 4 proteinuria (defined as $3+$ on dipstick, $>3.5 \mathrm{~g}$ of protein $/ 24$ hours, or the nephrotic syndrome) affects approximately $2 \%$ of treated patients. The incidence is not higher in patients who receive shorter bevacizumab infusions (i.e., 10 versus 90 minutes) $[82,83]$. The AEs of ramucirumab were lower than bevacizumab, with only $5.1 \%$ of patients experiencing proteinuria $[28,74]$.

Other less common renal problems that have been reported with bevacizumab include acute renal dysfunction and proliferative glomerulonephritis [27, 83].

Temporary cessation of bevacizumab is advised if protein excretion exceeds $2 \mathrm{~g}$ in 24 hours, and permanent discontinuation is appropriate for patients who develop the nephrotic syndrome [26]. 


\section{Enterotoxicity}

Enterocolitis, colitis, and gastrointestinal perforation (GIP) are common gastrointestinal AEs of MoAbs. In a study of pertuzumab monotherapy in patients with metastatic breast cancer, diarrhea of any grade developed in $48 \%$, but it was severe (grade 3 or 4 ) in only $3 \%[39,40]$. A phase III comparison of best supportive care (BSC) with or without panitumumab reported diarrhea of any grade in $21 \%$ of patients receiving this MoAb (grade 3: 1\%) compared to $11 \%$ with BSC alone (none grade 3) [18]. Cetuximab-related diarrhea is generally not severe, and while the rate of diarrhea of any grade was $12.7 \%$, rates of grade 3 or 4 diarrhea in studies of single agent cetuximab have ranged from only 1.5 to $2 \%$ $[17,84]$.

All VEGF targeted therapies, including bevacizumab, can cause gastrointestinal perforation (GIP). GIP has been reported in patients treated with bevacizumab for a variety of malignancies, and has occurred in $0.3 \%$ to $2.4 \%$ of clinical study patients receiving bevacizumab. It can occur anywhere along the GI tract. Nongastrointestinal fistula formation also has been observed, most commonly within the first 6 months of treatment. Most cases occur within 50 days of treatment initiation. In order to minimize the risk of GIP and fistula formation, at least 28 days (preferably six to eight weeks) should elapse between surgery and last dose of bevacizumab, except in emergency situations [85].

\section{Dermatologic/Cutaneous AEs}

8.1. Papulopustular Acneiform Eruption. The most common cutaneous reaction pattern with the EGFR inhibitors is a diffuse papulopustular acneiform eruption, which is due to a role of EGFR in maintaining integrity of the skin. It is noted in more than two-thirds of patients receiving any of these agents (cetuximab, panitumumab) $[17,18]$. The acneiform eruption is often dose-dependent, and typically begins early, within one week of treatment initiation. The lesions typically occur on the face, trunk, and extremities, sparing the palms and soles. Scaling of the interfollicular skin may also be present. Significant pruritus accompanies the cutaneous eruption in up to one-third of patients. Severity of the acneiform rash (all studies: $76 \%$ to $88 \%$; grades $3 / 4: 1 \%$ to $17 \%$; onset: $\leq 14$ days) correlates with treatment response and prolonged survival in colorectal cancer patients treated with cetuximab [86]. In the ASPECCT trial, Grade 3-4 skin AEs occurred in 62 patients (13\%) given panitumumab and 48 patients (10\%) given cetuximab [19]. The skin AEs of nimotuzumab were very low, with only mild moderate skin rash observed [20].

8.2. Paronychial Inflammation. Paronychia involving the great toe is often the first sign, and secondary bacterial infection (often with Staphylococcus aureus) is not uncommon in patients treated with cetuximab [17, 87]. Other less common specific cutaneous reactions include the following: erythematous exanthem caused by cytomegalovirus, Stevens-Johnson syndrome, toxic epidermal necrolysis, and full thickness necrosis, which has been reported in a small number of patients treated with ipilimumab for metastatic melanoma. Treatment options include topical antibiotics, topical corticosteroids, and/or electrodessication for larger lesions. Temporary withholding of the drug is appropriate when the cutaneous complication is serious [57].

8.3. Treatment. Preventive/prophylactic management is recommended: hydrocortisone $1 \%$ combined with moisturizer, sunscreen, and doxycycline $100 \mathrm{mg}$ bid for the first 6 weeks. Sunlight may exacerbate skin reactions (limit sun exposure). Treatment include the following: alclometasone $0.05 \%$ cream or fluocinonide $0.05 \%$ cream or clindamycin $1 \%$, and doxycycline $100 \mathrm{mg}$ bid or minocycline $100 \mathrm{mg}$ daily or isotretinoin at low doses (20-30 mg/day) [88].

8.4. Mucositis/Stomatitis. Mucositis or stomatitis is a frequent oral complication for cetuximab (grades 3/4: $0.9 \%$ ). It mostly affects the nonkeratinized labial and buccal mucosa, the mucosa of the tongue, of the floor of the mouth, and the soft palate and appears 9-16 days after treatment initiation, as this is the epithelial cell turnover time $[17,86]$. Stomatitis has been reported with bevacizumab (grades 1/2: 23\%) [89]. Tositumomab has a higher rate of severe mucositis than rituximab (52 versus 18\%) [50]. Other dermatologic toxicities include the following: maculopapular, erythematous rash, skinxerosis, pruritus, and Stevens-Johnson syndrome. Changes of the nails include pitting, discoloration, and onycholysis, with partial or complete loss of nails $[17,86,87]$.

\section{Cytopenia}

The most profound side effect of radioimmunotherapy (RIT) is potentially prolonged and significant cytopenia with cell count nadirs ranging from four to nine weeks posttherapy with recovery one to four weeks postnadir. The most common cytopenias are leukopenia and thrombocytopenia, which are easily managed in the majority of patients. RIT causes a transient depletion of B cells for approximately six to nine months. Severe and prolonged cytopenia, including both neutropenia and thrombocytopenia is common $[2,3]$.

Hematologic events during ofatumumab (CD20-directed $\mathrm{MoAb})$, brentuximab vedotin (CD30-directed MoAb), and alemtuzumab (CD52-directed MoAb) treatment included anemia, neutropenia, and thrombocytopenia. Neutropenia ( $\geq$ grade 3: $42 \%$; grade 4: $18 \%$; may be prolonged $>2$ weeks) and anemia (16\%; grades 3/4: $5 \%$ ) have been reported in treatment with ofatumumab. No patients discontinued the drug due to AEs [45]. Grade 3/4 bone marrow suppression may occur in treatment with brentuximab vedotin, as shown by neutropenia (20\%), thrombocytopenia ( $8 \%$ ), and anemia (6\%) [52-54]. Cytopenia in treatment with alemtuzumab includes the following: lymphopenia (grades 3/4: 97\%), neutropenia (77\%; grade $3 / 4: 42 \%$ to $64 \%$ ), anemia (76\%; grade $3 / 4: 12 \%$ to $38 \%$ ), and thrombocytopenia (71\%; grade $3 / 4$ : $13 \%$ to $52 \%$ ). Serious and fatal cytopenia (including pancytopenia, bone marrow hypoplasia, autoimmune hemolytic anemia, and autoimmune idiopathic thrombocytopenia) has occurred. Single doses $>30 \mathrm{mg}$ or cumulative weekly doses 
TABLE 4: Adverse events of 20 MoAbs.

\begin{tabular}{|c|c|c|c|}
\hline \multirow{2}{*}{$\mathrm{MoAb}$} & \multicolumn{2}{|c|}{ Adverse events } & \multirow{2}{*}{ Reference } \\
\hline & Systemic & Cutaneous & \\
\hline Cetuximab & $\begin{array}{l}\text { IR; cardiopulmonary arrest; GI; } \\
\text { pulmonary toxicity; hypomagnesemia; } \\
\text { infection; anaphylaxis }\end{array}$ & $\begin{array}{l}\text { Rash/desquamation; } \\
\text { acneiform rash; nail } \\
\text { changes; pruritus; } \\
\text { paronychial inflammation }\end{array}$ & {$[7,11,16,17]$} \\
\hline Panitumumab & $\begin{array}{l}\text { IR; pulmonary fibrosis; electrolyte } \\
\text { depletion; peripheral edema; GI; fatigue }\end{array}$ & $\begin{array}{l}\text { Erythema; acneiform rash; } \\
\text { pruritus; nail toxicity; } \\
\text { exfoliation; paronychia } \\
\text { skin fissures; } \\
\text { photosensitivity }\end{array}$ & {$[18,19]$} \\
\hline Nimotuzumab & $\begin{array}{l}\text { Fever; hypotension; tremor; } \\
\text { lymphopenia, }\end{array}$ & Rash and chills & {$[20,21]$} \\
\hline Bevacizumab & $\begin{array}{l}\text { Hypertension; VTE; ATE; GIP; } \\
\text { hemorrhage; wound healing } \\
\text { complications; fistula/abscess formation; } \\
\text { CHF; IR; } \\
\text { proteinurea; necrotizing fasciitis }\end{array}$ & $\begin{array}{l}\text { Exfoliative dermatitis; } \\
\text { xeroderma; alopecia }\end{array}$ & {$[22-27]$} \\
\hline Ramucirumab & $\begin{array}{l}\text { Hypertension; IR; ATE; GIP; } \\
\text { hemorrhage; } \\
\text { wound healing complications; RPIS }\end{array}$ & Skin rash & {$[28-30]$} \\
\hline Trastuzumab & $\begin{array}{l}\text { LVD;CHF; IR; pulmonary toxicity; } \\
\text { neutropenia; anaphylaxis/angioedema; } \\
\text { anemia; GI }\end{array}$ & $\begin{array}{l}\text { Acne vulgaris; nail } \\
\text { disorders; pruritus }\end{array}$ & {$[31-35]$} \\
\hline Trastuzumabemtansine & $\begin{array}{l}\text { Hepatotoxicity; LVD; pulmonary events; } \\
\text { thrombocytopenia; neurotoxicity; } \\
\text { hypersensitivity; IR; GI }\end{array}$ & Rash; pruritus & {$[36,37]$} \\
\hline Pertuzumab & $\begin{array}{l}\text { IR; cytopenias; GI; PN; } \\
\text { hypersensitivity/anaphylaxis; LVD }\end{array}$ & $\begin{array}{l}\text { Alopecia; rash; paronychia; } \\
\text { pruritus palmar-plantar } \\
\text { erythrodysesthesia; } \\
\text { xeroderma; pruritus }\end{array}$ & {$[38-40]$} \\
\hline Alemtuzumab & $\begin{array}{l}\text { Cytopenias; IR; infections; } \\
\text { immunogenicity; hypotension; } \\
\text { hypertension; dysrhythmia; pulmonary } \\
\text { events }\end{array}$ & Urticaria; rash; erythema; & {$[15,41,42]$} \\
\hline Rituximab & $\begin{array}{l}\text { IR; TLS; PML; renal toxicity; infections; } \\
\text { cardiac events; pulmonary events; bowel } \\
\text { obstruction/perforation; cytopenias; RA; } \\
\text { anaphylaxis; HBr; SS; PML }\end{array}$ & $\begin{array}{l}\text { Paraneoplastic pemphigus; } \\
\text { rash; pruritus; angioedema; } \\
\text { SJS; TEN }\end{array}$ & {$[5,12-14,43,44]$} \\
\hline Ofatumumab & $\begin{array}{l}\text { IR; cytopenias; intestinal obstruction; } \\
\text { PML; HBR; pneumonia; infections; } \\
\text { dyspnea; diarrhea; PML; TLS }\end{array}$ & $\begin{array}{l}\text { Rash; urticaria; } \\
\text { hyperhidrosis }\end{array}$ & {$[45,46]$} \\
\hline Obinutuzumab & $\begin{array}{l}\text { IR; hypocalcemia, hyperkalemia, } \\
\text { hyponatremia; cytopenias; hepatic } \\
\text { toxicity; infection; immunogenicity; } \\
\text { HBR; PML; TLS }\end{array}$ & None & {$[47,48]$} \\
\hline Ibritumomab & $\begin{array}{l}\text { IR; infections; severe cytopenias; } \\
\text { immunogenicity; secondary } \\
\text { malignancies; extravasation/radiation } \\
\text { necrosis }\end{array}$ & $\begin{array}{l}\text { EM; SJS; TeN; } \\
\text { exfoliativedermatitis; rash; }\end{array}$ & {$[8,49]$} \\
\hline Tositumomab & $\begin{array}{l}\text { Anaphylaxis; severe cytopenias; IR; } \\
\text { fetal harm; hypothyroidism; secondary } \\
\text { malignancies; infection }\end{array}$ & $\begin{array}{l}\text { Rash; pruritus; sweating; } \\
\text { dermatitis }\end{array}$ & {$[44,50,51]$} \\
\hline Brentuximab Vedotin & $\begin{array}{l}\text { PN; IR; cytopenias; TLS; } \\
\text { infectionimmunogenicity; } \\
\text { PML; anaphylaxis }\end{array}$ & SJS; rash; pruritus; alopecia & {$[52-55]$} \\
\hline
\end{tabular}


TABLE 4: Continued.

\begin{tabular}{|c|c|c|c|}
\hline \multirow{2}{*}{$\mathrm{MoAb}$} & \multicolumn{2}{|c|}{ Adverse events } & \multirow{2}{*}{ Reference } \\
\hline & Systemic & Cutaneous & \\
\hline Ipilimumab & IrAEs; diarrhea; fatigue; & $\begin{array}{l}\text { Dermatitis; pruritus; rash } \\
\text { SJS; TEN }\end{array}$ & {$[56,57]$} \\
\hline Catumaxomab & $\begin{array}{l}\text { SIRS; abdominal disorders; CRS; pyrexia; } \\
\text { cytopenias }\end{array}$ & $\begin{array}{l}\text { Rash; erythema; } \\
\text { pruritus }\end{array}$ & {$[58]$} \\
\hline Denosumab & $\begin{array}{l}\text { Hypocalcemia; hypophosphatemia; } \\
\text { embryo-fetal toxicity; ONJ and } \\
\text { osteomyelitis; fatigue; dyspnea }\end{array}$ & $\begin{array}{l}\text { Dermatitis; eczema; rash; } \\
\text { pruritus }\end{array}$ & {$[59,60]$} \\
\hline Nivolumab & Fatigue; diarrhea; lymphopenia & Rash; pruritus; vitiligo & [61] \\
\hline Siltuximab & $\begin{array}{l}\text { GIP; IR; IR/hypersensitivity reactions; } \\
\text { elevated hemoglobin levels; infection; } \\
\text { diarrhea }\end{array}$ & Pruritus; skin rash & {$[62]$} \\
\hline
\end{tabular}

CRS, cytokine release syndrome; GI, gastrointestinal symptoms, for example, nausea, diarrhea, vomiting, and constipation; HBR, hepatitis B reactivation; IrAEs, immune-mediated reactions due to T cell activation and proliferation (enterocolitis, hepatitis, dermatitis, neuropathies, and endocrinopathies); IR, infusion reactions; LVD, left ventricular dysfunction; ONJ, osteonecrosis of the jaw; PML, progressive multifocal leukoencephalopathy; PN, peripheral neuropathy; SIRS, systemic inflammatory response syndrome; SJS, Stevens-Johnson syndrome; SS, serum sickness-like reactions; RPIS, reversible posterior leukoencephalopathy syndrome; TEN, toxic epidermal necrolysis; TLS, tumor lysis syndrome.

$>90 \mathrm{mg}$ are associated with an increased incidence of pancytopenia $[15,41,42,90]$.

Treatment should be discontinued for serious hematologic or other serious toxicity (except lymphopenia) until the event resolves $[45,53,90]$.

\section{Other AEs}

Progressive multifocal leukoencephalopathy (PML) due to JC virus infection has been reported with rituximab use, which may be fatal. Cases were reported in patients receiving rituximab. With combination chemotherapy, PML onset maybe delayed, although most cases were diagnosed within 12 months of the last rituximab dose. Clinical findings included confusion/disorientation, motor weakness/hemiparesis, altered vision/speech, and poor motor coordination with symptoms progressing over weeks to months. Cases of reversible posterior leukoencephalopathy syndrome (RPLS) have been reported with VEGF antibodies, which may be fatal. Symptoms of RPLS include headache, seizure, confusion, lethargy, blindness and/or other vision change, or neurologic disturbances. Some of the other less common AEs associated with therapeutic monoclonal antibodies used for cancer therapy include the following: fatigue, vomiting, abdominal pain, anorexia, dysphonia, and peripheral neuropathy $[17,33,68,74,91]$. Cetuximab and pannitumumab can induce magnesium wasting resulting in clinically significant hypomagnesemia/hypokalemia and hypokalemia $[7,11,18]$.

\section{Other MoAbs in Ongoing Clinical Trials}

Two anti-PD-1 monoclonal antibodies, pembrolizumab and pidilizumab, have demonstrated activity in initial clinical trials in patients with advanced melanoma. Treatment AEs were manageable. The most common toxicities were fatigue, pruritus, rash, diarrhea, and arthralgia $(36,24,20,16$, and
$16 \%$, resp.). Overall $12 \%$ of patients experienced grade 3 or 4 AEs $[92,93]$. Anti-PD-1 monoclonal antibodies are currently being evaluated in randomized clinical trials. Clinical activity has been observed with several different anti-PD1-L1 monoclonal antibodies, including BMS-936559, MPDL3280A, BMS-936559, and MEDI4736, which has been evaluated in a dose escalation phase I trial with expansion cohorts in NSCLC, melanoma, and renal cell carcinoma [94, 95]. Further results from these studies are pending.

\section{Summary}

The panel of MoAbs that are approved by international regulatory agencies for the treatment of hematopoietic and solid malignancies has continued to expand. In this paper, we reviewed currently encompassing a stunning amount of 20 distinct molecules for 10 targets. We provide a brief scientific background on the use of MoAbs in cancer therapy, review all types of monoclonal antibodies-related adverse events (e.g., allergy, immune-related adverse events, cardiovascular adverse events, and pulmonary adverse events), and discuss the mechanism and treatment of adverse events (see Table 4).

Humanized monoclonal antibodies (MoAbs) have unique toxicities that differ from those of traditional chemotherapy. With the rapid development of targeted therapy to cancer, adverse events of MoAbs attract increasing attention. Further research is needed to explore the molecular mechanisms that underlie MoAb-related reactions to accurately identify hypersensitivity reactions and to develop new procedures for predicting AEs during MoAb treatment.

\section{Abbreviations \\ ADCC: Antibody-dependent cellular cytotoxicity \\ AEs: Adverse events \\ ARDS: Acute respiratory distress syndrome \\ ATE: Arterial thromboembolic event}


BALF: Bronchoalveolar lavage fluid

BOOP: Bronchiolitis obliterans organizing pneumonia

BSC: Best supportive care

CHF: Congestive heart failure

CTLA-4: Cytotoxic T lymphocyte-associated protein 4

CLL: Chronic lymphocytic leukemia

EGFR: Epidermal growth factor receptor

EpCAM: Epithelial cell adhesion molecule

FDA: Food and Drug Administration

HNC: Head and neck carcinoma

ILD: Interstitial lung disease

irAEs: Immune-related adverse events

LVEF: Left ventricular ejection fraction

MoAb: Monoclonal antibody

NHL: Non-Hodgkin's lymphoma

NSCLC: Non-small cell lung carcinoma

PD-1: $\quad$ Programmed death 1 protein

RPLS: Reversible posterior leukoencephalopathy syndrome

SIR: $\quad$ Standard infusion reaction

T-DM1: Trastuzumabemtansine

VEGF: Vascular endothelial growth factor

VTE: Venous thromboembolic event.

\section{Disclosure}

Mei Guan and Yan-Ping Zhou are co-first authors.

\section{Conflict of Interests}

There are no potential conflict of interests to disclose.

\section{References}

[1] A. Muraro, G. Roberts, and M. Worm, "Anaphylaxis: guidelines from the European Academy of Allergy and Clinical Immunology," Allergy, vol. 69, pp. 1026-1045, 2014.

[2] Zevalin, FDA: Full Prescribing Information. Adverse Reactions, 2013, http://www.accessdata.fda.gov/drugsatfda_docs/label/ 2009/125019s0156.pdf.

[3] Bexxar, FDA: Full prescribing information. Adverse reactions, 2013, http://www.accessdata.fda.gov/drugsatfda_docs/label/ 2012/125011s102lbl.pdf.

[4] E. R. Gomes and P. Demoly, "Epidemiology of hypersensitivity drug reactions," Current Opinion in Allergy and Clinical Immunology, vol. 5, no. 4, pp. 309-316, 2005.

[5] E. Kimby, "Tolerability and safety of rituximab (MabThera)," Cancer Treatment Reviews, vol. 31, no. 6, pp. 456-473, 2005.

[6] M. Castells, "Rapid desensitization for hypersensitivity reactions to medications," Immunology and Allergy Clinics of North America, vol. 29, no. 3, pp. 585-606, 2009.

[7] C. H. Chung, B. Mirakhur, E. Chan et al., "Cetuximab-induced anaphylaxis and IgE specific for galactose- $\alpha$-1,3- galactose," The New England Journal of Medicine, vol. 358, no. 11, pp. 1109-1117, 2008.

[8] R. Jankowitz, J. Joyce, and S. A. Jacobs, "Anaphylaxis after administration of ibritumomab tiuxetan for follicular nonHodgkin lymphoma," Clinical Nuclear Medicine, vol. 33, no. 2, pp. 94-96, 2008.
[9] T. Rispens, N. I. L. Derksen, S. P. Commins, T. A. Platts-Mills, and R. C. Aalberse, "IgE Pro- ductiontoa-Gal is accompanied by elevated levels of specific IgG1 antibodies and low amounts of IgE to blood group B," PLoS ONE, vol. 8, no. 2, Article ID e55566, 2013.

[10] E. A. Berg, T. A. Platts-Mills, and S. P. Commins, "Drug allergens and food-the cetuximab and galactose- $\alpha$-1, 3-galactose story," Annals of Allergy, Asthma \& Immunology, vol. 112, no. 2, pp. 97-101, 2014.

[11] C. H. Chung, B. Mirakhur, E. Chan et al., "Cetuximab-induced anaphylaxis and IgE specific for galactose- $\alpha$-1,3- galactose," The New England Journal of Medicine, vol. 358, no. 11, pp. 1109-1117, 2008.

[12] P. McLaughlin, A. J. Grillo-López, B. K. Link et al., "Rituximab chimeric anti-CD20 monoclonal antibody therapy for relapsed indolent lymphoma: half of patients respond to a four-dose treatment program," Journal of Clinical Oncology, vol. 16, no. 8, pp. 2825-2833, 1998.

[13] A. Sandhu, A. Harford, and P. Singh, "Is thymoglobulin or rituximab the cause of this serum sickness? A case report of serum sickness dilemma and literature review," Case Reports in Medicine, vol. 2012, Article ID 234515, 7 pages, 2012.

[14] G. Le Guenno, M. Ruivard, L. Charra, and P. Philippe, "Rituximab-induced serum sickness in refractory immune thrombocytopenic purpura," Internal Medicine Journal, vol. 41, no. 2, pp. 202-205, 2011.

[15] M. J. Keating, I. Flinn, V. Jain et al., “Therapeutic role of alemtuzumab (Campath-1H) in patients who have failed fludarabine: results of a large international study," Blood, vol. 99, no. 10, pp. 3554-3561, 2002.

[16] A. Shablak and A. Conn, "A case of fatal cetuximab-induced interstitial lung disease during the first weeks of treatment," Targeted Oncology, vol. 9, no. 2, pp. 177-180, 2014.

[17] D. Cunningham, Y. Humblet, S. Siena et al., "Cetuximab monotherapy and cetuximab plus irinotecan in irinotecanrefractory metastatic colorectal cancer," The New England Journal of Medicine, vol. 351, no. 4, pp. 337-345, 2004.

[18] E. Van Cutsem, M. Peeters, S. Siena et al., "Open-label phase III trial of panitumumab plus best supportive care compared with best supportive care alone in patients with chemotherapyrefractory metastatic colorectal cancer," Journal of Clinical Oncology, vol. 25, no. 13, pp. 1658-1664, 2007.

[19] T. J. Price, M. Peeters, T. W. Kim et al., "Panitumumab versus cetuximab in patients with chemotherapy-refractory wild-type KRAS exon 2 metastatic colorectal cancer (ASPECCT): a randomised, multicentre, open-label, non-inferiority phase 3 study," The Lancet Oncology, vol. 15, no. 6, pp. 569-579, 2014.

[20] D. Strumberg, B. Schultheis, M. E. Scheulen et al., "Phase II study of nimotuzumab, a humanized monoclonal antiepidermal growth factor receptor (EGFR) antibody, in patients with locally advanced or metastatic pancreatic cancer," Investigational New Drugs, vol. 30, no. 3, pp. 1138-1143, 2012.

[21] B. K. Reddy, V. Lokesh, M. S. Vidyasagar et al., "Nimotuzumab provides survival benefit to patients with inoperable advanced squamous cell carcinoma of the head and neck: a randomized, open-label, phase IIb , 5-year study in Indian patients," Oral Oncology, vol. 50, no. 5, pp. 498-505, 2014.

[22] E. Tan-Chiu, G. Yothers, E. Romond et al., "Assessment of cardiac dysfunction in a randomized trial comparing doxorubicin and cyclophosphamide followed by paclitaxel, with or without trastuzumab as adjuvant therapy in node-positive, human epidermal growth factor receptor 2-overexpressing breast cancer: 
NSABP B-31," Journal of Clinical Oncology, vol. 23, no. 31, pp. 7811-7819, 2005.

[23] S. R. Nalluri, D. Chu, R. Keresztes, X. Zhu, and S. Wu, "Risk of venous thromboembolism with the angiogenesis inhibitor bevacizumab in cancer patients: a meta-analysis," The Journal of the American Medical Association, vol. 300, no. 19, pp. 2277$2285,2008$.

[24] T. K. Choueiri, E. L. Mayer, Y. Je et al., "Congestive heart failure risk in patients with breast cancer treated with bevacizumab," Journal of Clinical Oncology, vol. 29, no. 6, pp. 632-638, 2011.

[25] P. Y. Zuo, X. L. Chen, and Y. W. Liu, "Increased risk of cerebrovascular events in patients with cancer treated with bevacizumab: a meta-analysis," PLoS ONE, vol. 9, no. 7, Article ID e102484, 2014.

[26] A. F. C. Okines, R. E. Langley, L. C. Thompson et al., "Bevacizumab with peri-operative epirubicin, cisplatin and capecitabine (ECX) in localised gastro-oesophageal adenocarcinoma: a safety report," Annals of Oncology, vol. 24, no. 3, Article ID mds533, pp. 702-709, 2013.

[27] S. M. Gressett and S. R. Shah, "Intricacies of bevacizumab induced toxicities and their management," Annals of Pharmacotherapy, vol. 43, no. 3, pp. 490-501, 2009.

[28] C. S. Fuchs, J. Tomasek, C. J. Yong et al., "Ramucirumab monotherapy for previously treated advanced gastric or gastrooesophageal junction adenocarcinoma (REGARD): an international, randomised, multicentre, placebo-controlled, phase 3 trial," The Lancet, vol. 383, no. 9911, pp. 31-39, 2014.

[29] A. X. Zhu, R. S. Finn, M. Mulcahy et al., "A phase II and biomarker study of ramucirumab, a human monoclonal antibody targeting the VEGF receptor-2, as first-line monotherapy in patients with advanced hepatocellular cancer," Clinical Cancer Research, vol. 19, no. 23, pp. 6614-6623, 2013.

[30] J. A. Garcia, G. R. Hudes, T. K. Choueiri et al., "A phase 2, single-arm study of ramucirumab in patients with metastatic renal cell carcinoma with disease progression on or intolerance to tyrosine kinase inhibitor therapy," Cancer, vol. 120, no. 11, pp. 1647-1655, 2014.

[31] M. S. Ewer, M. T. Vooletich, J.-B. Durand et al., "Reversibility of trastuzumab-related cardiotoxicity: new insights based on clinical course and response to medical treatment," Journal of Clinical Oncology, vol. 23, no. 31, pp. 7820-7826, 2005.

[32] M. Procter, T. M. Suter, E. de Azambuja et al., "Longer-term assessment of trastuzumab-related cardiac adverse events in the Herceptin Adjuvant (HERA) trial," Journal of Clinical Oncology, vol. 28, no. 21, pp. 3422-3428, 2010.

[33] X. L. Du, R. Xia, K. Burau, and C. C. Liu, "Cardiac risk associated with the receipt of anthracycline and trastuzumab in a large nationwide cohort of older women with breast cancer, 1998-2005," Medical Oncology, vol. 28, supplement 1, pp. S80S90, 2011.

[34] B. Vahid and A. Mehrotra, "Trastuzumab (Herceptin)associated lung injury," Respirology, vol. 11, no. 5, pp. 655-658, 2006.

[35] Herceptin (trastuzumab for injection), FDA approved package insert. US National Library of Medicine, 2010, http://www .dailymed.nlm.nih.gov/.

[36] S. Verma, D. Miles, L. Gianni et al., “Trastuzumabemtansine for HER2-positive advanced breast cance," The New England Journal of Medicine, vol. 367, no. 19, pp. 1783-1791, 2012.

[37] S. Girish, M. Gupta, B. Wang et al., "Clinical pharmacology of trastuzumab emtansine (T-DM1): an antibody-drug conjugate in development for the treatment of HER2-positive cancer," Cancer Chemotherapy and Pharmacology, vol. 69, no. 5, pp. 1229-1240, 2012.

[38] J. Corteś, P. Fumoleau, G. Bianchi et al., "Pertuzumab monotherapy after trastuzumab-based treatment and subsequent reintroduction of trastuzumab: activity and tolerability in patients with advanced human epidermal growth factor receptor 2-positive breast cancer," Journal of Clinical Oncology, vol. 30, no. 14, pp. 1594-1600, 2012.

[39] L. Gianni, T. Pienkowski, Y. H. Im et al., "Efficacy and safety of neoadjuvant pertuzumab and trastuzumab in women with locally advanced, inflammatory, or early HER2-positive breast cancer ( NeoSphere ): a randomised multicentre, open-label, phase 2 trial," The Lancet Oncology, vol. 13, pp. 25-32, 2012.

[40] J. Abraham and M. Stenger, "Pertuzumab in neoadjuvant treatment of HER2-positive early breast cancer," Journal of Community and Supportive Oncology, vol. 12, no. 3, pp. 84-86, 2014.

[41] A. De Masson, P. Guitera, P. Brice et al., "Long-term efficacy and safety of alemtuzumab in advanced primary cutaneous Tcell lymphomas," British Journal of Dermatology, vol. 170, no. 3, pp. 720-724, 2014.

[42] T. Elter, L. Gercheva-Kyuchukova, H. Pylylpenko et al., "Fludarabine plus alemtuzumab versus fludarabine alone in patients with previously treated chronic lymphocytic leukaemia: a randomised phase 3 trial," The Lancet Oncology, vol. 12, no. 13, pp. 1204-1213, 2011.

[43] H. Lioté, F. Lioté, B. Séroussi et al., "Rituximab-induced lung disease: a systematic literature review," European Respiratory Journal, vol. 35, no. 3, pp. 681-687, 2010.

[44] O. W. Press, J. M. Unger, L. M. Rimsza et al., "Phase III randomized intergroup trial of $\mathrm{CHOP}$ plus rituximab compared with $\mathrm{CHOP}$ chemotherapy plus 13liodine-tositumomab for previously untreated follicular non-hodgkin lymphoma: SWOG S0016," Journal of Clinical Oncology, vol. 31, no. 3, pp. 314-320, 2013.

[45] Y. Ogawa, M. Ogura, T. Suzuki et al., "A phase I/II study of ofatumumab (GSK1841157) in Japanese and Korean patients with relapsed or refractory B-cell chronic lymphocytic leukemia," International Journal of Hematology, vol. 98, no. 2, pp. 164-170, 2013.

[46] W. G. Wierda, T. J. Kipps, J. Mayer et al., "Ofatumumab as singleagent CD20 immunotherapy in fludarabine-refractory chronic lymphocytic leukemia," Journal of Clinical Oncology, vol. 28, no. 10, pp. 1749-1755, 2010.

[47] F. A. Morschhauser, G. Cartron, C. Thieblemont et al., "Obinutuzumab (GA101) monotherapy in relapsed/refractory diffuse large b-cell lymphoma or mantle-cell lymphoma: results from the phase II GAUGUIN study," Journal of Clinical Oncology, vol. 31, no. 23, pp. 2912-2919, 2013.

[48] J. Radford, A. Davies, G. Cartron et al., "Obinutuzumab (GA101) plus CHOP or FC in relapsed/refractory follicular lymphoma: results of the GAUDI study (B021000)," Blood, vol. 122, no. 7, pp. 1137-1143, 2013.

[49] F. Morschhauser, J. Radford, A. Van Hoof et al., "90Yttriumibritumomab tiuxetan consolidation of first remission in advanced-stage follicular non-Hodgkin lymphoma: updated results after a median follow-up of 7.3 years from the International, Randomized, Phase III First-LineIndolent trial," Journal of Clinical Oncology, vol. 31, no. 16, pp. 1977-1983, 2013.

[50] J. M. Vose, S. Carter, L. J. Burns et al., "Phase III randomized study of rituximab/ carmustine, etoposide, cytarabine, and 
melphalan (BEAM) compared with iodine-131 tositumomab /BEAM with autologous hematopoietic cell transplantation for relapsed diffuse large B-cell lymphoma: results from the BMT CTN 0401 trial," Journal of Clinical Oncology, vol. 31, pp. 16621668, 2013.

[51] B. K. Link, P. Martin, M. S. Kaminski, S. J. Goldsmith, M. Coleman, and J. P. Leonard, "Cyclophosphamide, vincristine, and prednisone followed by tositumomab and iodine-131tositumomab in patients with untreated low-grade follicular lymphoma: eight-year follow-up of a multicenter phase II study," Journal of Clinical Oncology, vol. 28, no. 18, pp. 30353041, 2010.

[52] M. A. Fanale, A. Forero-Torres, J. D. Rosenblatt et al., "A phase I weekly dosing study of brentuximab vedotin in patients with relapsed/refractory CD30-positive hematologic malignancies," Clinical Cancer Research, vol. 18, no. 1, pp. 248-255, 2012.

[53] A. Younes, A. K. Gopal, S. E. Smith et al., "Results of a pivotal phase II study of brentuximabvedotin for patients with relapsed or refractory Hodgkin's lymphoma," Journal of Clinical Oncology, vol. 30, no. 18, pp. 2183-2189, 2012.

[54] T. Siddiqi, S. H. Thomas, and R. Chen, "Role of brentuximabvedotin in the treatment of relapsed or refractory Hodgkin lymphoma," Pharmacogenomics and Personalized Medicine, vol. 7, pp. 79-85, 2014.

[55] A. Younes, J. M. Connors, S. I. Park et al., "Brentuximabvedotin combined with ABVD or AVD for patients with newly diagnosed Hodgkin's lymphoma: a phase 1, open-label, doseescalation study," The Lancet Oncology, vol. 14, pp. 1348-1356, 2013.

[56] L. A. Fecher, S. S. Agarwala, F. Stephen Hodi, and J. S. Weber, "Ipilimumab and its toxicities: a multidisciplinary approach," The Oncologist, vol. 18, no. 6, pp. 733-743, 2013.

[57] F. S. Hodi, S. J. O’Day, D. F. McDermott et al., "Improved survival with ipilimumab in patients with metastaticmelanoma," The New England Journal of Medicine, vol. 363, pp. 711-723, 2010.

[58] M. M. Heiss, P. Murawa, P. Koralewski et al., "The trifunctional antibody catumaxomab for the treatment of malignant ascites due to epithelial cancer: results of a prospective randomized phase II/III trial," International Journal of Cancer, vol. 127, no. 9, pp. 2209-2221, 2010.

[59] S. Adami, C. Libanati, S. Boonen et al., "Denosumab treatment in postmenopausal women with osteoporosis does not interfere with fracture-healing: results from the FREEDOM trial," Journal of Bone and Joint Surgery A, vol. 94, no. 23, pp. 2113-2119, 2012.

[60] D. H. Henry, L. Costa, F. Goldwasser et al., "Randomized, double-blind study of denosumab versus zoledronic acid in the treatment of bone metastases in patients with advanced cancer (excluding breast and prostate cancer) or multiple myeloma," Journal of Clinical Oncology, vol. 29, no. 9, pp. 1125-1132, 2011.

[61] S. L. Topalian, M. Sznol, D. F. McDermott et al., "Survival, durable tumor remission, and long-term safety in patients with advanced melanoma receiving nivolumab," Journal of Clinical Oncology, vol. 32, no. 10, pp. 1020-1030, 2014.

[62] R. Kurzrock, P. M. Voorhees, C. Casper et al., "A phase I, open-label study of siltuximab, an anti-IL-6 monoclonal antibody, in patients with B-cell non-hodgkin lymphoma, multiple myeloma, or castleman disease," Clinical Cancer Research, vol. 19, no. 13, pp. 3659-3670, 2013.

[63] M. C. Castells, N. M. Tennant, D. E. Sloane et al., "Hypersensitivity reactions to chemotherapy: outcomes and safety of rapid desensitization in 413 cases," Journal of Allergy and Clinical Immunology, vol. 122, no. 3, pp. 574-580, 2008.

[64] F. Torino, A. Barnabei, L. de Vecchis, R. Salvatori, and S. M. Corsello, "Hypophysitis induced by monoclonal antibodies to cytotoxic T lymphocyte antigen 4: challenges from a new cause of a rare disease," Oncologist, vol. 17, no. 4, pp. 525-535, 2012.

[65] S. M. Corsello, A. Barnabei, P. Marchetti, L. De Vecchis, R. Salvatori, and F. Torino, "Endocrine side effects induced by immune checkpoint inhibitors," The Journal of Clinical Endocrinology \& Metabolism, vol. 98, no. 4, pp. 1361-1375, 2013.

[66] S. L. Topalian, F. S. Hodi, J. R. Brahmer et al., "Safety, activity, and immune correlates of anti-PD-1 antibody in cancer," New England Journal of Medicine, vol. 366, no. 26, pp. 2443-2454, 2012.

[67] A. Ribas, F. S. Hodi, R. Kefford et al., "Efficacy and safety of the anti-PD-1 monoclonal antibody pembrolizumab (MK-3475) in 411 patients (pts) with melanoma (MEL)," in Proceedings of the American Society of Clinical Oncology Meeting (ASCO '14), 2014, (Abstract LBA9000).

[68] H. Hurwitz, L. Fehrenbacher, W. Novotny et al., "Bevacizumab plus irinotecan, fluorouracil, and leucovorin for metastatic colorectal cancer," The New England Journal of Medicine, vol. 350, no. 23, pp. 2335-2342, 2004.

[69] I. E. Krop, S. B. Kim, A. González-Martín et al., “TH3RESA study collaborators Trastuzumabemtansine versus treatment of physician's choice for pretreated HER2-positive advanced breast cancer (TH3RESA): a randomised, open-label, phase 3 trial," The Lancet Oncology, vol. 15, no. 7, pp. 689-699, 2014.

[70] P. Madeddu, "Therapeutic angiogenesis and vasculogenesis for tissue regeneration," Experimental Physiology, vol. 90, no. 3, pp. 315-326, 2005.

[71] E. S. Robinson, E. V. Khankin, T. K. Choueiri et al., "Suppression of the nitric oxide pathway in metastatic renal cell carcinoma patients receiving vascular endothelial growth factor-signaling inhibitors," Hypertension, vol. 56, no. 6, pp. 1131-1136, 2010.

[72] H. Izzedine, S. Ederhy, F. Goldwasser et al., "Management of hypertension in angiogenesis inhibitor-treated patients," Annals of Oncology, vol. 20, no. 5, pp. 807-815, 2009.

[73] R. Dienstmann, I. Braña, J. Rodon, and J. Taberanero, “Toxicity as a biomarker of efficacy of molecular targeted therapies: focus on EGFR and VEGF inhibiting anticancer drugs," Oncologist, vol. 16, no. 12, pp. 1729-1740, 2011.

[74] J. A. Garcia, G. R. Hudes, T. K. Choueiri et al., "A phase 2, single-arm study of ramucirumab in patients with metastatic renal cell carcinoma with disease progression on or intolerance to tyrosine kinase inhibitor therapy," Cancer, vol. 120, no. 11, pp. 1647-1655, 2014.

[75] F. A. Scappaticci, J. R. Skillings, S. N. Holden et al., "Arterial thromboembolic events in patients with metastatic carcinoma treated with chemotherapy and bevacizumab," Journal of the National Cancer Institute, vol. 99, pp. 1232-1239, 2007.

[76] J.-Y. Pierga, T. Petit, T. Delozier et al., "Neoadjuvant bevacizumab, trastuzumab, and chemotherapy for primary inflammatory HER2-positive breast cancer (BEVERLY-2): an openlabel, single-arm phase 2 study," The Lancet Oncology, vol. 13, no. 4, pp. 375-384, 2012.

[77] C. Criscitiello, O. Metzger-Filho, K. S. Saini et al., "Targeted therapies in breast cancer: are heart and vessels also being targeted?" Breast Cancer Research, vol. 14, no. 3, article 209, 2012.

[78] E. Radzikowska, E. Szczepulska, M. Chabowski, and I. Bestry, "Organising pneumonia caused by transtuzumab (Herceptin) 
therapy for breast cancer," European Respiratory Journal, vol. 21, no. 3, pp. 552-555, 2003.

[79] M. J. Pepels, K. A. Boomars, R. van Kimmenade, and P. S. Hupperets, "Life-threatening interstitial lung disease associated with trastuzumab: case report," Breast Cancer Research and Treatment, vol. 113, no. 3, pp. 609-612, 2009.

[80] H. Izzedine, C. Massard, J. P. Spano, F. Goldwasser, D. Khayat, and J. C. Soria, "VEGF signalling inhibition-induced proteinuria: mechanisms, significance and management," European Journal of Cancer, vol. 46, no. 2, pp. 439-448, 2010.

[81] V. Eremina, J. A. Jefferson, J. Kowalewska et al., "VEGF inhibition and renal thrombotic microangiopathy," The New England Journal of Medicine, vol. 358, no. 11, pp. 1129-1136, 2008.

[82] G. Bollée, N. Patey, G. Cazajous et al., "Thrombotic microangiopathy secondary to VEGF pathway inhibition by sunitinib," Nephrology Dialysis Transplantation, vol. 24, no. 2, pp. 682-685, 2009.

[83] J.-M. Halimi, M. Azizi, G. Bobrie et al., "Vascular and renal effects of anti-angiogenic therapy," Nephrologie et Therapeutique, vol. 4, no. 7, pp. 602-615, 2008.

[84] R. Pirker, J. R. Pereira, J. von Pawel et al., "EGFR expression as a predictor of survival for first-line chemotherapy plus cetuximab in patients with advanced non-small-cell lung cancer: analysis of data from the phase 3 FLEX study," The Lancet Oncology, vol. 13, no. 1, pp. 33-42, 2012.

[85] S. E. Borofsky, M. S. Levine, S. E. Rubesin, J. L. Tanyi, C. S. Chu, and A. S. Lev-Toaff, "Bevacizumab-induced perforation of the gastrointestinal tract: clinical and radiographic findings in 11 patients," Abdominal Imaging, vol. 38, no. 2, pp. 265-272, 2013.

[86] T. Li and R. Perez-Soler, "Skin toxicities associated with epidermal growth factor receptor inhibitors," Targeted Oncology, vol. 4, no. 2, pp. 107-119, 2009.

[87] T. Eames, B. Grabein, J. Kroth, and A. Wollenberg, "Microbiological analysis of epidermal growth factor receptor inhibitor therapy-associated paronychia," Journal of the European Academy of Dermatology and Venereology, vol. 24, no. 8, pp. 958-960, 2010.

[88] M. E. Lacouture, M. J. Anadkat, R.-J. Bensadoun et al., "Clinical practice guidelines for the prevention and treatment of EGFR inhibitor-associated dermatologic toxicities," Supportive Care in Cancer, vol. 19, no. 8, pp. 1079-1095, 2011.

[89] F. Kabbinavar, H. I. Hurwitz, L. Fehrenbacher et al., "Phase II, randomized trial comparing bevacizumab plus fluorouracil (FU)/leucovorin (LV) with FU/LV alone in patients with metastatic colorectal cancer.," Journal of Clinical Oncology, vol. 21, no. 1, pp. 60-65, 2003.

[90] C. D. Schweighofer and C.-M. Wendtner, "First-line treatment of chronic lymphocytic leukemia: role of alemtuzumab," Onco Targets and Therapy, vol. 3, pp. 53-67, 2010.

[91] W. Wang, L. R. Zhao, X. Q. Lin, and F. Feng, "Reversible posterior leukoencephalopathy syndrome induced by bevacizumab plus chemotherapy in colorectal cancer," World Journal of Gastroenterology, vol. 20, no. 21, pp. 6691-6697, 2014.

[92] M. B. Atkins, R. R. Kudchadkar, M. Sznol et al., "Phase 2, multicenter, safety and efficacy study of pidilizumab in patients with metastatic melanoma," in Proceedings of the American Society of Clinical Oncology Meeting (ASCO '14), 2014, abstract no. 9001 .

[93] B. C. Creelan, "Update on immune checkpoint inhibitors in lung cancer," Cancer Control, vol. 21, no. 1, pp. 80-89, 2014.
[94] J. R. Brahmer, S. S. Tykodi, L. Q. M. Chow et al., "Safety and activity of anti-PD-L1 antibody in patients with advanced cancer," The New England Journal of Medicine, vol. 366, no. 26, pp. 2455-2465, 2012.

[95] P. A. Ascierto, M. Kalos, D. A. Schaer, M. K. Callahan, and J. D. Wolchok, "Biomarkers for immunostimulatory monoclonal antibodies in combination strategies for melanoma and other tumor types," Clinical Cancer Research, vol. 19, no. 5, pp. 10091020, 2013. 

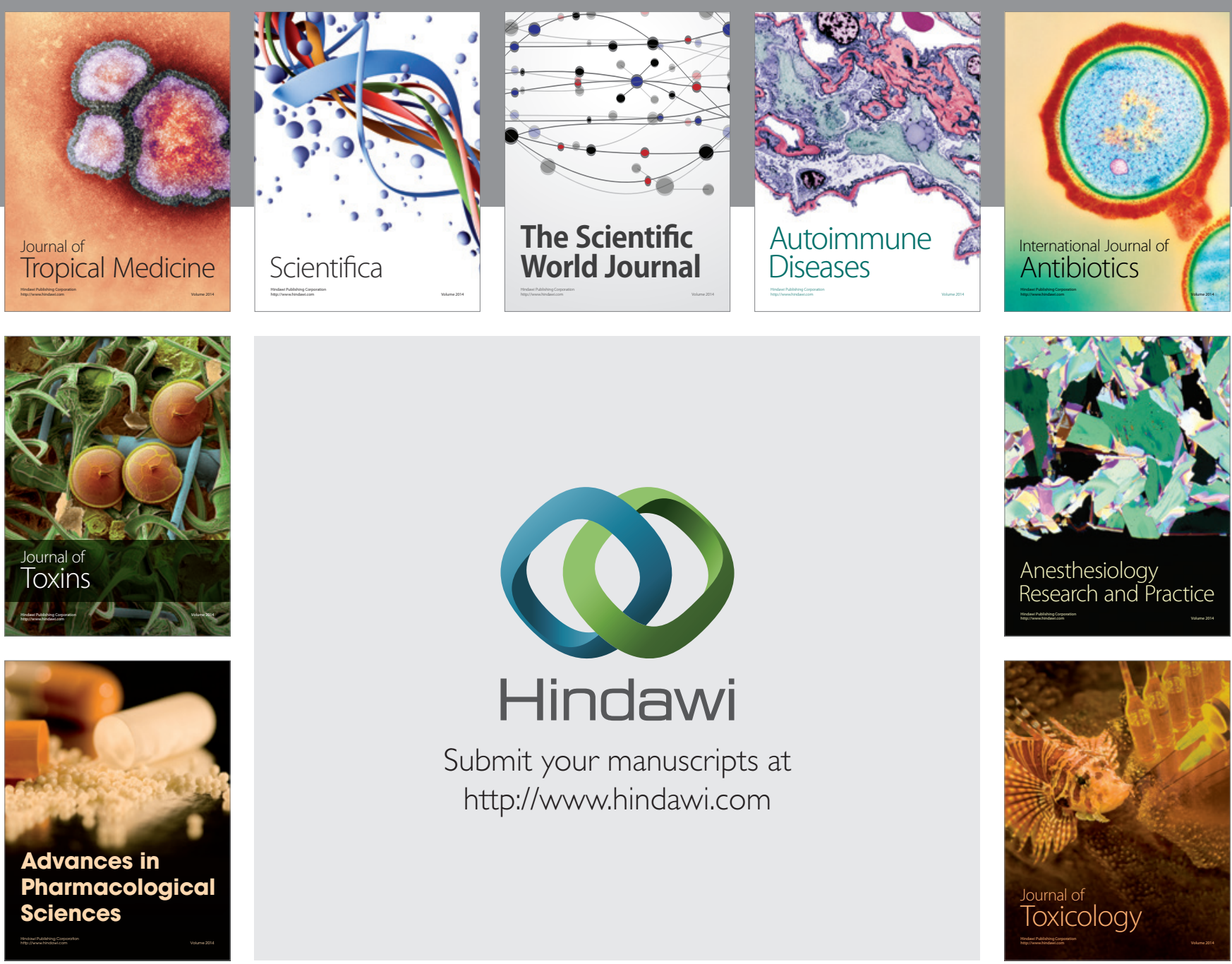

\section{Hindawi}

Submit your manuscripts at

http://www.hindawi.com
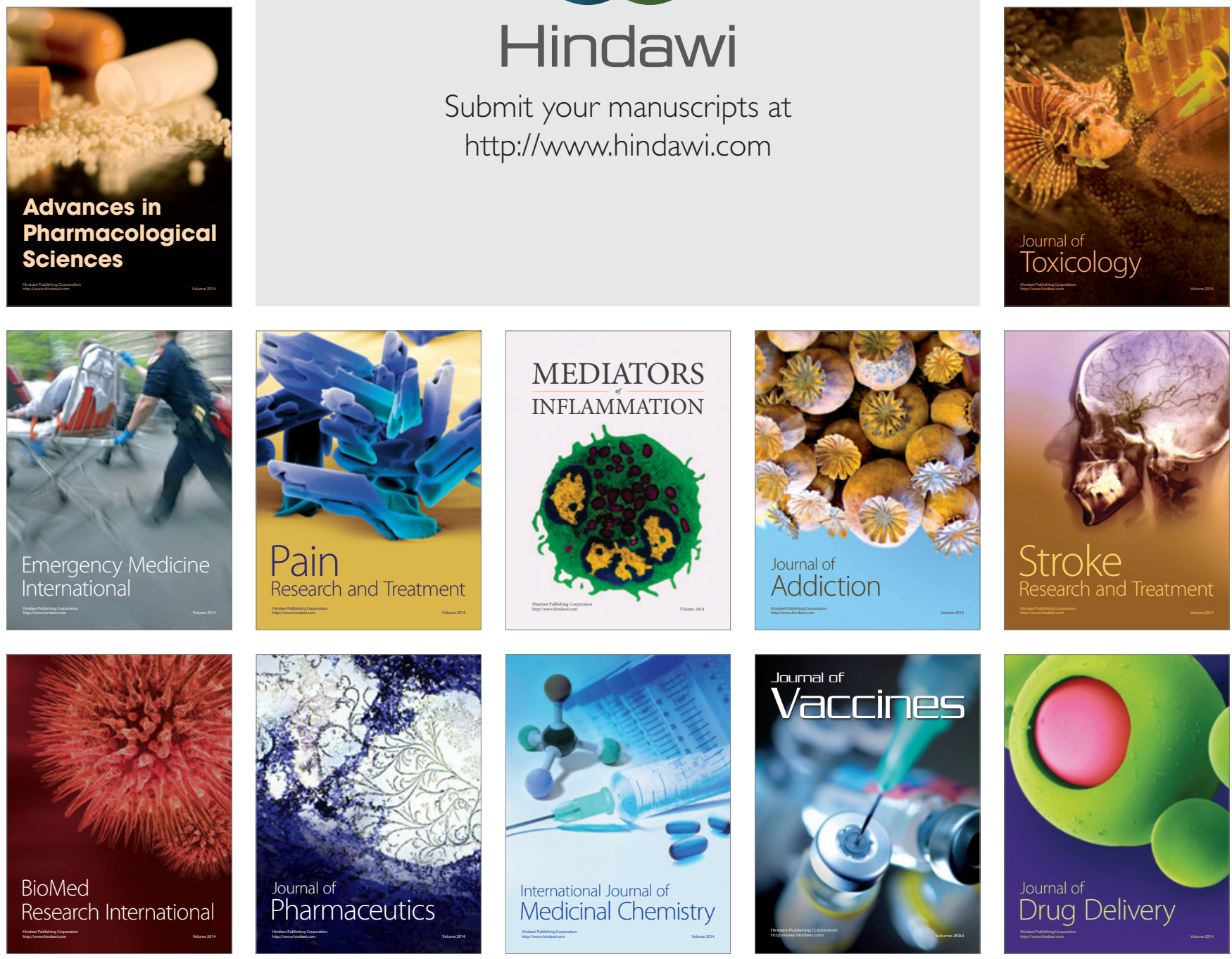